\section{DIAGNOSTIC LABORATORY HEMATOLOGY}

By G. E. Cartwright, M.D. Pp. vii + ro4, illustrated. London: Grune and Stratton. I954. $\$ 3.00$.

Dr. Cartwright, who is well known as a haematologist and as $M$. Wintrobe's second-in-command at Salt Lake City, has produced a very useful book on practical haematology. It is designed to be helpful in students' laboratories and in the doctor's surgery. It, therefore, does not make the fundamental mistake, which many books of similar size and scope commit, of being designed for both technicians and medical students. The attitude to techniques varies with individual investigators, but little fault can be found with Dr. Cartwright's book. This reviewer is particularly pleased to see the definite and dogmatic statement that of the methods for the detection of anaemia ' the enumeration of the red cells is the least accurate and the most difficult and time consuming to perform.' Clinicians unfortunately often forget this fact, or, worse still, often do not know it. Perhaps it is a little surprising to find the Sahli method for the determination of haemoglobin regarded as the method of choice, but this may be due to the absence of gas or electricity services in large areas of the United States. The sources of error given with each method are very useful, but would appeal more to the technician's needs. The absence of any mention of the prothrombin time or of its simple and reasonably reliable one-stage-estimation should perhaps be remedied in a second edition, which will almost certainly appear in due course. Three points in the section on the bone marrow should be mentioned. Sections of aspirated marrow material are advisable and are, indeed, often invaluable. Surgical biopsy is not necessary in order to obtain a histological section. The statement, that 'the. diagnosis of pernicious anaemia can generally be made with reasonable certainty without resorting to marrow examination,' must be emphatically refuted. It is just because megaloblasts disappear from the marrow so soon after the application of the haemopoietic principle, and because the presence of megaloblasts is the most important evidence of pernicious anaemia apart from the reticulocyte crisis and the prompt recovery with treatment, that no patient with suspected pernicious anaemia should ever be started on treatment without bone marrow biopsy. When a decision is to be made whether a patient with idiopathic thrombocytopenic purpura is likely to benefit from splenectomy, the presence or absence of megakaryocytes and their precursors in the marrow is often a helpful piece of information. Yet Dr. Cartwright states that marrow aspiration is of little or no diagnostic value in haemorrhagic disorders.

Almost all the tables in this book are reliably arranged and compiled, and didactically sound. It is good to know that in yet another American book on haematology instead of the ugly terms for the blood and marrow cells devised by some committee the conventional terms have been used.

This book should certainly. fulfil its function well and will be welcome in all laboratories.

E.N.

\section{TUMOURS OF LYMPHOID TISSUE}

By G. Lumb, M.D. Pp. viii + 204, illustrated. Edinburgh: E. \& S. Livingstone Ltd. I 954. 37s. $6 \mathrm{~d}$.

Study of the lymph glands and of lymphoid $\varrho$ tissue seems to have an appeal particularly to the $\overrightarrow{\overrightarrow{0}}$ younger pathologist. A classification almost always accompanies published studies on this problem and it is sometimes said that later on, this is frequently regretted by the originator. In the foreword Sir Stanford Cade states that 'Dr. Lumb succeeds in presenting a classification without confusing the already-confused nomenclature and by introducing only one new name, "reticular lymphoma":3 This reviewer cannot help feeling that Dr. Lumb might have done better if he refrained from introducing this one new name since this entity is after 음 all only a benign close relative of Hodgkin's disease. But, of course, the whole essence of the book might have broken down if this course had been pursued.

The first four chapters of this book deal in a $\mathrm{N}$ semi-conventional manner with structure, function, terminology and incidence of the tumours of $\bigcirc$ lymphoid tissue, but there are many statements $\omega$ which are not supported by reference to published $\sigma$ work and indeed many statements which ask for $\hat{\theta}$ violent disagreement and some which are definitely $\frac{\bar{\Phi}}{\Phi}$ wrong, like the one that plasma cells constitute I to 3 per cent. of the cells of the normal human marrow. They are very rare, and even in such conditions as rheumatoid arthritis they do not often exceed 2 per cent. 
The 410 cases which the author has studied at Westminster Hospital are split up into the various groups in Tables 1 to 5 , but to present the threeyear survival rates in figures with two decimals (for example 12 cases $=16.66$ per cent.) seems futile. To present age incidence both in the form of a table and as a graph is not permitted by any medical journal, but it is done here on pages 30 and $3 \mathbf{r}$.

Chapters 5 to 10 are taken up by descriptions of the tumours: follicular lymphoma, lymphosarcoma, reticular lymphoma, Hodgkin's disease, reticulum cell sarcoma and anaplastic sarcoma. Dr. Lumb regards lymphosarcoma and lymphatic leukaemia as really much the same disease entity and this opinion will be shared by many.

Chapter I I deals with problems of diagnosis. It is astonishing to find no mention of the Haematoxylin and van Gieson's method in paragraphs dealing with staining. After all it is probably the best to show fibrosis, which is such a feature in many cases of Hodgkin's disease. In the classification of the leukaemias, discussed in the section of the differential diagnosis, " chronic monocytic leukaemia' is mentioned, though no case of ' monocytic leukaemia' has ever survived more than two or three months and it is even doubtful if such an entity really exists. The extremely rare basophilic leukaemia is mentioned, but the author does not appear to have heard of erythraemic myelosis (Di. Guglielmo's disease). More than 60 photographs illustrate other malignant and granulomatous lesions such as Gaucher's disease, Brucellosis, torulosis, histoplasmosis and Boeck's sarcoidosis, but they do not seem really within the scope of the work.

The effects of treatment on primary tumours of lymphoid tissue are discussed in a very short chapter, but the effects of ACTH or cortisone are not even mentioned.

The details of 19 cases used to illustrate the features of the morbid states described are given in the final chapter.

The book is lavishly illustrated and well produced. It is irritating to find the same cell in three photographs (Figs. I, 8; I, I IA and 8, I 8) and some of the pictures are not really helpful, but most are of good quality and some are really excellent. The tables vary in value, but Table $I I$ is an example of how not to make a table. Under ten headings, material observed appears only in four columns, leaving six empty spaces!

The style is conventional, but there are annoying mannerisms. Cells do not occur in sheets. This would indicate a two-dimensional spread only. They really occur in masses.

A lot of material has provided the basis for this book, but one gains the impression that though the main headings have been rightly selected, more attention to details and more care in the preparation of the manuscript might have produced a much more worthwhile treatise.

E.N.

\section{CLINICAL BACTERIOLOGY}

By E. JoAN Stokes, M.B., B.S., M.R.C.P., M.R.C.S. Pp. vii +288 , with 25 illustrations. London: Edward Arnold, Ltd. 1955. 20s.

A well produced, usefully tabulated and diagrammed book, compact and modestly priced.

The subject is well covered, all commonly and not a few uncommonly needed techniques being included.

The methods are those of one particular laboratory; therefore not everyone will agree with some of the finer points of the methods described. For routine work many will regard some of the identification techniques as too detailed and time consuming, but no one can quarrel with them as an ideal to be aimed at when time and cost are no object.

Junior staff will find this book a good bench companion and a reference more easily and rapidly handled than the larger works. In addition it forms, with its bibliography, an adequate framework upon which to build when studying for the postgraduate diplomas in pathology.

The general clinician and surgeon will find much of use and value in the chapters on antibacterial drugs and Hospital Epidemiology; this latter chapter should also be read by those about to qualify as it will save them much trouble later on.

For those who wish to gain a rapid insight intes the scope of modern bacteriological practice as of operates in Britain today, I can recommend ne better book.

\section{GYNAECOLOGY}

By Douglas H. MacLeod, M.S., F.R.C.P., F.R.C.S., F.R.C.O.G. and-Charles D. READ, M.B., F.R.C.S., F.R.A.C.S. Fifth Edition. Pp. 864; with 55I illustrations, 27 in colour. London: J. \& A. Churchill Ltd. I955. 80s.

This book has long been awaited. For the first time it is now possible to prepare for the higher examinations in gynaecology without having to have recourse to an American textbook.

The authors, who are probably two of the most successful and skilful gynaecological surgeons in London today, have combined their experience to produce a work that is practical in the extreme, and 9 yet reveals the deepest perusal of the academic literature of the subject. It is eminently readable.

The chapter on anatomy by Mr. Snyder surely does fulfil the hopes of the editors that it is accept- $N$ able to the anatomists as well as the gynaecologists. What is more, it is easier to follow than most anatomical works.

The chapter on physiology makes clear some of the confusing modern knowledge of the $\operatorname{sex} 0$

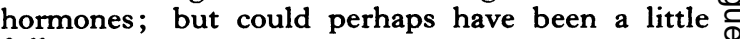
fuller.

A textbook of this nature meets its severest test, possibly, when it comes to discuss ovarian tumours. The classification given by the authors is reasonable, and the several chapters devoted to the pathology 